\title{
BIOMECHANICAL ASSESSMENT OF THE MOTOR ACTION OF THE TECHNIQUE SEOI NAGE IN THE JUDO SPORT
}

\author{
N. Dimitrova* \\ Department of Foreign Languages and Information Technologies, National Sports Academy \\ "Vassil Levski", Sofia, Bulgaria
}

\begin{abstract}
An "active" experiment has been realized for cinematic and dynamographic analyses of the motor action with one of the basic judo techniques of Kyu-dan system Seoi nage. From one hand the general common and legal principles assuring the success of the technique are respected and the individual particularities demonstrated during the performance of elite sportsman. The aim of the present work is research and realization of complex biomechanical analyses of the technique Seoi nage. The cinematic characteristics are assessed from quantity point of view with the help of videocomputing methods and the dynamic ones by using measurement of the supporting reactions on the dynamograhic platform. Two elite competitors for whom Seoi nage represents the basic technique are taking part in the research. The results followed the performance are common biomechanical regularities and important individual particularities in the sport technical mastership. The obtained results are followed by questions to the training process concerning the measurement between the standards and the individualization of the sport technical mastership.
\end{abstract}

Key words: Kyu-dan, judo techniques, , individual approach, technical mastership

\section{INTRODUCTION}

The basic principle for the biomechanical analysis in the judo is the concept for Seiryoku Zenyo. Seiryoki Zenyo is the most effective use of the strength of the mind and the body. (1) The inspiration so to say is the best way to be used as a personal energy and also the power of the environment. The energy includes the power of the mind and the body. This is the basic judo principle by Kano Jigoro $(2,3)$. The technical activities in the judo are dynamic systems of the movement itself based on the defense and the attack. (4).

It is well known depending on the individual particularities of the supporting motor/biomechanical and psychophysiological/ ones during the activities of each athlete we can always find something typically characteristic -this is he individual style of the competitor. It is of a great interest

\footnotetext{
*Correspondence to: Nikolina Dimitrova,National Sports Academy, Sofia, Department for Foreign Languages and Information Technologies, Studentski grad 1700 Sofia, Bulgaria, E-mail ninansa@abv.bg
}

to find out the theoretic difference between sport technique and style. The performance of the movements is an independent characteristic of the technical mastership and it does not depend from the effective point of view as we can perform technique which is not effective. The performing level is assessed through the stability of the sport result, the stability against the variable external conditions, the conservation of the supporting skills and automised ones. Obviously we are witnessing for optimum level of the structural level relationship measurements having in mind the concept for stability-variability and the standard-individualisation of the sport technical mastership. $(5,6)$.

One of the basic te waza techniques is seoi nage which is the leading one regarding the frequency and the efficiency during the competition performance in the school-training work. $(7,8)$, And regardless of the position of the seoi nage in the ranking list efficiency (always on the top) its importance is a leading one for the improvement of the sport technical mastership. 
The basic aim of the present research is to accomplish a complex biochemical analysis of the technique Seoi nage.

\section{METHODS}

With the use of cinematographic and dynamographic analysis are studied the common legal principles providing the success of the technique from one hand and the individual particularities demonstrated during the performance of the elite athletes.

The analysis and the study of different parts of the techniques requires very good knowledge of the different phases. The general structure $(2,9)$ includes:

- First phase - Kuzushi- Balance breaking

- Second phase - Tsukuri -Set-up to execute technique - The ainm of this phase is to break the freedom of movements through Kuzushi uke in balance breaking.

- Third phase- Kake - Execution of techniques

Cinematic characteristics are assessed on a quantitative point of vue with the help of video computer methods and the dynamic characteristics are done through measuring the reactions on dynamic-graphic platform.

Two best athletes with the same weight category are selected for the research and for them the technique Seoi nage is the basic one from the technical and strategy point of view. More than 30 performances have been analyzed in standard laboratory conditions.

\section{RESULTS AND DISCUSSION}

\section{Theoritical analyses}

It is important to note each phase has his own private aim helping to solve the biomechanical performance task of the basic goal itself. Each phase has got one or more quantitative biomechanical characteristics. Therefore the phases are having quantitave assessment of the efficiency during their performance. It is possible to follow the so called alternative errors which usually remain hidden for the external observer.

Having in mind the above mentioned the efficiency of the judo techniques depends on:

1. Position of the attack
a. Kumi Kata- hold
b. Shizei- posture
c. Angle of the attack
d. Distance of yke

The technique Seoi nage is shown (Figure 1a). From starting with Migi-shizen-tai- right natural posture, tori steps with the right foot and imposes to uke using the power of the hold to step back with the left foot (Figure 1a and Figure 2). This practice moment coincide with Kuzushi. (Jigoro Kano, 2013)

The beginning of the attak (Tsukuri) should start before the left foot of uke steps on the tatami. For that purpose tori places his right foot forward next to the right one of uke and immediately afterwards performing an arc movement places his left foot altogether with his right one. After the end of Tsukuri the feet of uke and tori are located in parallel. When rotating tori pulls out all the time the opponent with his left hand using the arc movement

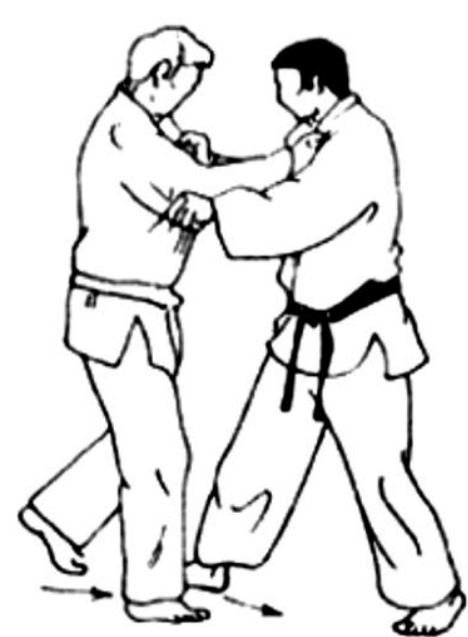

fig.1 a

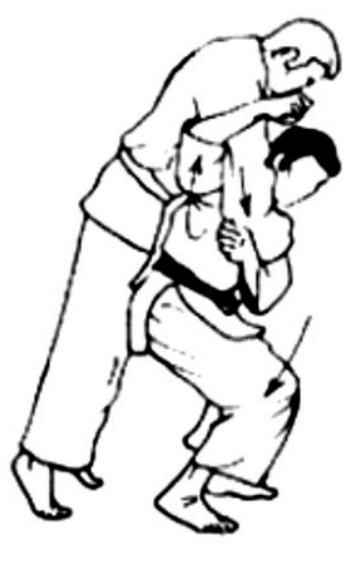

fig.1 b

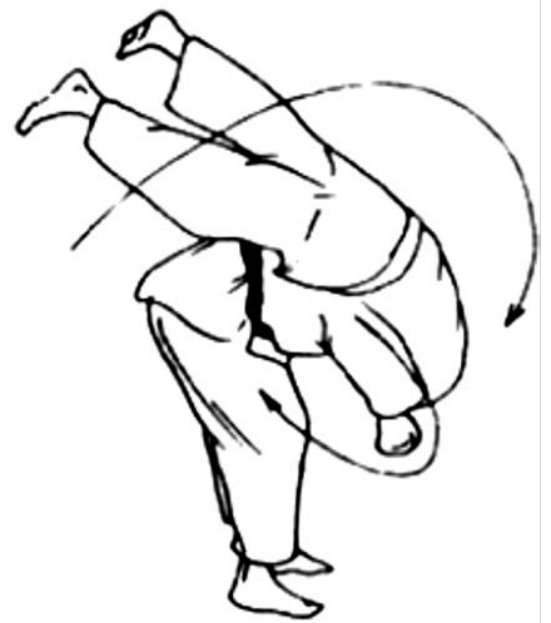

fig.1 c

Figure 1. 


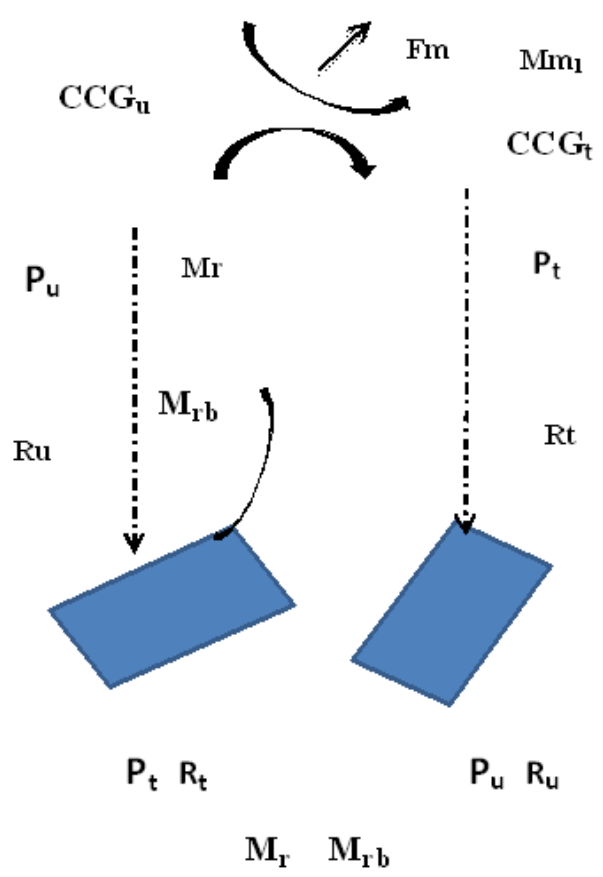

Figure 2. Force structure of seoi nage in starting position Migi-shizen-tai

And the right hand goes in deeply around the chest or the right forearm of uke (Figure 1b) The throwing -kake (Figure 1c) is realized when the hip is lifted immediately and powerful stretch out of the feet. In order to assure more effective power tori should create very close contact among his back and uke's chest.
After Kuzushi on the uke's body are activated the force FM and the weight of the athlete with applied to the point in center of gravity, FM the power of the hold with the left hand directed forward and around tori's body and also providing support of the accomplished Kuzushi (Figure 3).
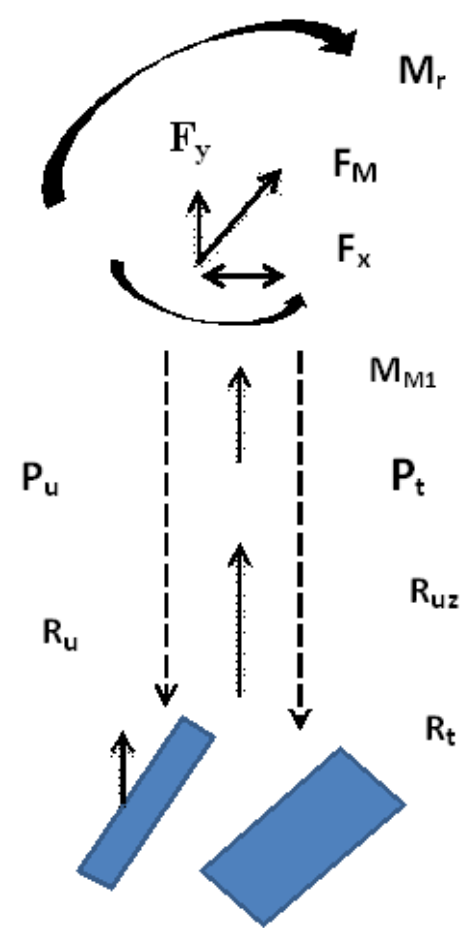

$$
\mathrm{P}_{\mathrm{u}} \mathrm{R}_{\mathrm{u}+} \mathrm{R}_{\mathrm{uz}} \quad \mathrm{R}_{\mathrm{t}} \mathrm{P}_{\mathrm{t}+} \mathrm{R}_{\mathrm{tz}}
$$

Figure 3. Force structure of seoi nage in phase Kuzushi 
This power depends till great extent from the cinematic in the positions of the two bodies. Therefore FM is composed from the rotating moment $\mathbf{M r}$ of $\mathbf{F M}$ and the resistance from Mrb (uke's weight). And then the absolute value $\mathbf{M r}$ is not so important but the accomplishment of the rotating moment realized by the tori's weight comparing with those of uke.

The power directed on vertically position has got the task to decrease this resistance moment and it is considered as a mistake if the tori's
DIMIROVA N.

right forearm is not situated parallelly under the uke's shoulder.

The throwing (Figure1 c) kake is realized through the "two" powers $\boldsymbol{F}_{\boldsymbol{M}}^{\prime}$ and $\boldsymbol{F}_{\boldsymbol{M}}^{\prime \prime}$. (Figure 4) Therefore $\boldsymbol{F}_{\boldsymbol{M}}^{\prime \prime}$ identification is quite difficult as this is the result from the support reaction, the inertion power and weight from both athletes. Besides this power is not concentrated only in one support point and the vector of the rotation moment could be determined from the exterior cinematic picture using video-computer analysis.

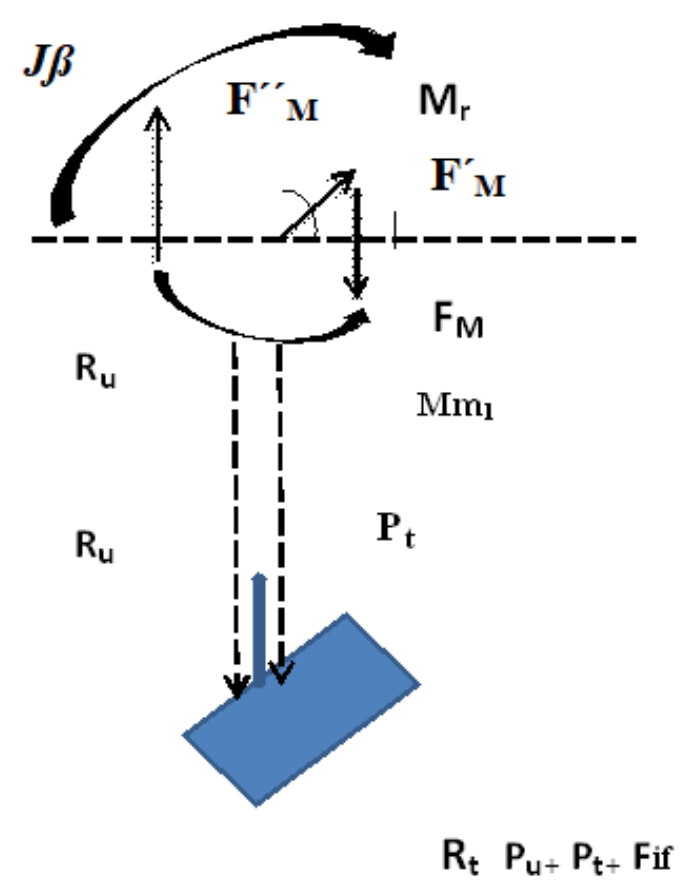

Figure 4 Summary diagram of the force structure of Uke and Tori in the phase "Kake"

The time for reaction (different kinds) the management and the coordination of the different parts and cinematic chains in the supporting point, adequate structure time management including the orientation according to the environment (psychology). These parameters remain hidden for the theoretical analyses and could be assessed only with adequate laboratory experiments.

The psycho-motor parameters represent different weight concerning the management of the supporting activities. We can mention also the concentration abilities on the sound information when we are having aggressive background, sound location, assessment of surface different positions, peripheral eyesight. The above- mentioned could be done with additional research program works.
The statistical analyses of the dynamic structure are quite important thanks to their individualization. The experience related to the statistics has difficulties because of the high values of variable coefficients $(17,4-\mathrm{V} \%$ 31,2 ). And the internal force structure is submitted to several individual abilities for each athlete. We should bear in mind the quantative value of the biomechanical ability. The attack depends on the biomechanical and anatomic particularities of uke.

In Table 1 are presented the results from the variable analysis of the basic power characteristics of the tested athletes. Obviously One of the competitors counts more on gradient of the power vectors for Kuzushi performance and the other one prepares the attack by blocking uke level movements for freedom. Also the angle differences in the 
power sector for Tsukuri $\left(68^{0}\right.$ for the first athlet and $59^{\circ}$ for the second one) till great extent determine some differences in the absolute values of the supporting reactions. Some important differences are found out and
DIMIROVA N. directed of the axe Z. Although the direction is not oriented to the throwing itself the compensatory mechanisms and the stability of the techniques are respected.

Table 1. of variable analysis seoi nage

\begin{tabular}{|c|c|c|c|c|c|c|c|c|c|}
\hline \multirow{2}{*}{\multicolumn{2}{|c|}{$\begin{array}{c}\text { Athlet } \\
\text { (characteristics) }\end{array}$}} & \multicolumn{4}{|c|}{ Athlete A } & \multicolumn{4}{|c|}{ Athlete B } \\
\hline & & Phase I & $\mathrm{V} \%$ & Phase II & $\mathrm{V} \%$ & Phase I & $\mathrm{V} \%$ & Phase II & $\mathrm{V} \%$ \\
\hline \multicolumn{2}{|c|}{$\begin{array}{l}\text { Timing Phases } \\
\text { (Hundreds of seconds) }\end{array}$} & 38 & 8,7 & 114 & 5,3 & 49 & 6,2 & 134 & 2,3 \\
\hline \multirow{3}{*}{$F_{\max }$} & $x$ & 120 & 5,8 & 290 & 5,1 & 85 & 5,3 & 260 & 5,1 \\
\hline & \begin{tabular}{|l|}
$y$ \\
\end{tabular} & 740 & 7,6 & 1660 & 11,8 & 680 & 5,2 & 1640 & 6,9 \\
\hline & $z$ & 120 & 2,3 & 205 & 7,9 & 125 & 4,7 & 140 & 4,7 \\
\hline \multirow{3}{*}{$t$ for $F_{\max }$} & $x$ & 19 & 1,8 & 45 & 10,3 & 25 & 3,4 & 62 & 5,9 \\
\hline & $y$ & 21 & 2,1 & 50 & 2,2 & 23 & 1,1 & 70 & 2,3 \\
\hline & $z$ & 19 & 2,8 & 42 & 2,8 & 29 & 3,3 & 85 & 3,4 \\
\hline \multirow{3}{*}{ Impulses of $\boldsymbol{F}_{\max }$} & $x$ & 49 & 4,6 & 22 & 5,9 & 50 & 4,5 & 26 & 5,9 \\
\hline & \begin{tabular}{|l|}
$y$ \\
\end{tabular} & 102 & 6,7 & 220 & 5,8 & 112 & 1,6 & 260 & 5,8 \\
\hline & $z$ & 46 & 2,9 & 66 & 3,2 & 52 & 5,3 & 72 & 4,5 \\
\hline \multirow{3}{*}{ Grad. of $\boldsymbol{F}_{\text {max }}$} & $x$ & 26 & 2,6 & 56 & 8,1 & 18 & 1,9 & 86 & 5,3 \\
\hline & $y$ & 32 & 2,3 & 72 & 2,7 & 16 & 0,8 & 70 & 1,3 \\
\hline & $z$ & 50 & 3,1 & 52 & 3,1 & 28 & 2,4 & 48 & 3,8 \\
\hline
\end{tabular}

When the hold is performed starting from static positioning laboratory conditions, the values of the variable coefficients measure the level of the automatic technique.

\section{CONCLUSIONS}

All judokas perform the techniques with their specific and individual particularities. Therefore Kyu-Dan system should be studied only in the beginning of the training, when we are having high sport mastership the individual skills are the most important.

1. The biomechanics abilities for the different athletes are based on different coordinating structures providing compensating mechanisms in order to stabilize the supporting system.

2. The sport technical mastership could be measured in many other ways and it is hard to assess it only on the admitted classic dynamographic analysis on the tori power vector.

3. On the other hand the statistical methods for the assessment and the efficiency of the judo different techniques are not the most important in the management field and improvement of the sport-technical mastership. The leading ones are the individual biomechanical particularities of the determined competitor.

4. The biomechanical abilities for the different athletes are defined with the help of different coordination structures providing the compensating mechanisms to stabilize the supporting system. The experiments prove the necessity of redefining the concepts for realized efficiency of the supporting qualities and biomechanics abilities of the sport technique.

\section{Dictionary}

Kake - Execution of techniques

Kuzushi- Balance breaking

Migi-shizen-tai- Right natural posture

Tatami-Mat

Tori- Player executing technique

Tsukuri-Set up to execute technique

Uke- Player receiving opponent's attack.

Seoi nage - Shoulder throw- (Technique)

\section{REFERENCES}

1. Albert E., M. Albert, "The role of gigong to develop specific performance judo", Sport, stress, adaptation extra issue ISSN 2367-3393.

2. Jigoro Kano; Kodokan Judo: The Essential Guide to Judo by Its Founder Jigoro Kano Paperback -Japan Publications Trading Company; August 30, 2013

3. Ivanov, Sv., P. Bogdanov (1973) Learn Judo; Medicine and Physical Education, Sofia (In Bulgarian)

4. Kudo K. 1977, "Judo in Action". Throwing techniques. Japan Publications Trading Company. Tokyo.. P.20. 
5. Donskoy, D.D., Zatsiorsky, V.M. Biomechanics: Textbook for institutes of physical culture. - Moscow: Fizkultura i sport, 1979. - 264 P. (In Russian)

6. Ivanov,Sv. (1989) Theory and methods of biomemechanical analysis in the sport field. Research work,Sofia, (In Bulgarian)

7. Prokopov E., Classification and Analysis of Judo Throwing Techniques, Yearbook of Sofia University, vol. 84, S., "St. Kliment Ohridski ", 2004, ISSN 0205-0692, pp. 3342 (In Bulgarian)
8. Dimitrova N., Nikolova A.; Dikova, P., 2018, Classification Structure of the throwing techniques in Judo (nage waza) Scientific Conference "Challenges and Prospects to Sports Science" "Problems to Modern Sport", S. 2018, pp. 59-65; Sports $\&$ Science; extraordinary number 1 ; ISSN 1310-3393

9. Prokopov E., (2005), Judo - philosophy, history, structure, essence, "St. Kliment Ohridski ", Sofia. IBSN 954-07-2284-5 (In Bulgarian) 